\title{
Transferability and characterization of simple sequence repeat markers from Anacardium occidentale to A. humile (Anacardiaceae)
}

\author{
L.G. Cota ${ }^{1,2}$, P.A. Moreira ${ }^{1}$, E.V. Menezes ${ }^{1,3}$, A.S. Gomes ${ }^{1}$, A.R.O. Ericsson ${ }^{3}$, \\ D.A. Oliveira ${ }^{1,2,3}$ and A.F. Melo Jr., ${ }^{1,3}$ \\ ${ }^{1}$ Laboratório de Bioprospecção e Recursos Genéticos, \\ Departamento de Biologia Geral, Universidade Estadual de Montes Claros, \\ Montes Claros, MG, Brasil \\ ${ }^{2}$ Programa de Pós-Graduação em Ciências Biológicas, \\ Universidade Estadual de Montes Claros, Montes Claros, MG, Brasil \\ ${ }^{3}$ Programa de Pós-Graduação em Biotecnologia, \\ Universidade Estadual de Montes Claros, Montes Claros, MG, Brasil \\ Corresponding author: D.A. Oliveira \\ E-mail: dario.oliveira@unimontes.br
}

Genet. Mol. Res. 11 (4): 4609-4616 (2012)

Received March 28, 2012

Accepted June 20, 2012

Published October 17, 2012

DOI http://dx.doi.org/10.4238/2012.October.17.7

\begin{abstract}
Use of molecular markers can be limited by the high cost and extensive time required for their development. Transfer of simple sequence repeat (SSR) markers reduces the cost and time limitations and has allowed the use of these markers in a larger number of species. We tested 11 SSR markers previously developed for Anacardium occidentale on A. humile. The 11 loci were successfully amplified in A. humile. All loci were polymorphic and generated a mean of 5.4 alleles per locus. The observed heterozygosity was lower than the expected heterozygosity under Hardy-Weinberg equilibrium for most loci, with mean values of 0.463 and 0.696 , respectively. The endogamy coefficients were positive and significant for seven loci.
\end{abstract}


However, the combined probability of paternity exclusion was high, and the combined probability of genetic identity was low. None of the pairs of loci were in linkage disequilibrium. The informative power of these loci demonstrates that they are suitable for studies of diversity and genetic structure of natural populations of A. humile. In addition, the loci are suitable for estimating gene flow between populations, assessing species crossing preferences, and performing interspecific comparisons.

Key words: SSR markers; "Cajuzinho-do-cerrado"; Transferability; Genetic analyses

\section{INTRODUCTION}

Anacardium humile Saint Hilaire, known as monkey nut "cajuzinho-do-cerrado", is a fruit species native to areas of the Cerrado biome. This species produces a highly sought after nut and pseudofruit and has characteristics and uses similar to the common cashew ( $A$. occidentale), which is the only species of the genus that is grown and distributed throughout the tropical world (Almeida et al., 1998; Vieira et al., 2006).

A. humile is typically a tropical species that is resistant to environmental stresses and has biological, socioeconomic, and medical importance (Almeida et al., 1998; Londe et al., 2007). This species also has the general attributes of native fruit, such as nutritional food value (Ribeiro and Rodrigues, 2006). The species may become vulnerable to conditions that include rampant extractivism and degradation of native habitats. Moreover, the lack of studies on the population characteristics may pose an even greater threat to the survival of the species over time and space. Therefore, the use of tools for analyzing the genetic patterns of natural populations is critical for preserving the existing levels of genetic variation in the species. Microsatellite markers, or simple sequence repeats (SSRs), are short DNA sequences of 1 to 6 pairs of nucleotides that are repeated in tandem and scattered throughout the genomes of eukaryotes and can be found in prokaryotes (Tautz, 1989; Weber and May, 1989; Ellegren, 2004). Microsatellite markers are very popular in population genetic studies (Barbará et al., 2007; Guichoux et al., 2011) because of codominance and their highly polymorphic and informative nature. Polymorphisms arise from the high mutation rates in microsatellite regions and result primarily from variability in length rather than variability in the main sequence (Weber and May, 1989; Tautz, 1989). The use of microsatellite markers in several studies has generated data regarding the diversity and genetic structure of natural populations, dispersal patterns of genes, crossbreeding systems, effective population-size, and evolutionary relationships between species. The use of these markers has provided basic knowledge of evolution and has promoted conservation, sustainable use, breeding, and genetic mapping of species (Zucchi et al., 2003; Hardy et al., 2006; Ellis and Burke, 2007; Takezaki and Nei, 2008; Cristofani-Yaly et al., 2011).

Several studies have shown that the homology of DNA sequences in microsatellite flanking-region pairs has allowed SSR markers that have been developed for one species to be transferred to another species of the same genus or even different genera (Zucchi et al., 2002; Ciampi et al., 2008; Ekué et al., 2009; Feres et al., 2009; Litrico et al., 2009; Elazreg et al., 
2011; Cristofani-Yaly et al., 2011). The success of marker transfer is inversely proportional to the evolutionary distance between the 2 species (Schlotterer et al., 1991; Moore et al., 1991; FitzSimmons et al., 1995; Rossetto, 2001). Transferability between related species also allows the assessment of loci not included in the isolation of microsatellites in a species and/or the assessment of loci in species with a low frequency of repetitive regions, which complicates the isolation of loci (Oliveira et al., 2006). Considering the possibility of transferring markers between related species, we study aimed to evaluate the potential for using SSR markers previously developed for $A$. occidentale in A. humile and to characterize the SSR markers for this species.

\section{MATERIAL AND METHODS}

\section{DNA extraction and amplification of SSR loci}

Forty adult A. humile individuals were collected for the analysis of transferability and characterization of microsatellite loci in areas of Cerrado, where they naturally occur (the northern part of the State of Minas Gerais, Brazil). Genomic DNA was isolated from the leaf tissue of each individual by following the methodology proposed by Doyle and Doyle (1987).

The amplification of 11 SSR loci, previously developed for $A$. occidentale (Croxford et al., 2006) (Table 1), was analyzed using polymerase chain reaction (PCR) in A. humile. The PCRs were performed using a final volume of $15 \mu \mathrm{L}$ containing $1 \mathrm{X}$ buffer $(10 \mathrm{mM}$ Tris- $\mathrm{HCl}$, $\mathrm{pH} 8.4$, and $50 \mathrm{mM} \mathrm{KCl}$ ), $0.7 \mu \mathrm{M}$ of each pair of primers, $0.25 \mathrm{mM}$ dNTPs, $1 \mathrm{U}$ Taq DNA polymerase, $0.25 \mathrm{mg}$ bovine serum albumin, the optimal concentrations of $\mathrm{MgCl}_{2}(\mathrm{mM})$ and formamide (\%) for each pair of primers, and 9 ng DNA.

\begin{tabular}{|c|c|c|c|c|}
\hline Locus & Primer sequence $\left(5^{\prime}-3^{\prime}\right)$ & Motif repetition & $\operatorname{Tm}\left({ }^{\circ} \mathrm{C}\right)$ & AAS (bp) \\
\hline mAoR03 & $\begin{array}{l}\text { F: CAGAACCGTCACTCCACTCC } \\
\text { R: ATCCAGACGAAGAAGCGATG }\end{array}$ & $(\mathrm{AC})_{12}(\mathrm{AAAAT})_{2}$ & 68 & $\begin{array}{c}241-291 \\
(241-247)\end{array}$ \\
\hline mAoR06 & $\begin{array}{l}\text { F: CAAAACTAGCCGGAATCTAGC } \\
\text { R: CCCCATCAAACCCTTATGAC }\end{array}$ & $(\mathrm{AT})_{5}(\mathrm{GT})_{12}$ & 58 & $\begin{array}{l}160-168 \\
(143-157)\end{array}$ \\
\hline mAoR07 & $\begin{array}{l}\text { F: AACCTTCACTCCTCTGAAGC } \\
\text { R: GTGAATCCAAAGCGTGTG }\end{array}$ & $(\mathrm{AT})_{2}(\mathrm{GT})_{5} \mathrm{AT}(\mathrm{GT})_{5}$ & 59 & $\begin{array}{c}200-220 \\
(178-181)\end{array}$ \\
\hline mAoR11 & $\begin{array}{l}\text { F: ATCCAACAGCCACAATCCTC } \\
\text { R: CTTACAGCCCAAACTCTCG }\end{array}$ & $(\mathrm{AT})_{3}(\mathrm{AC})_{16}$ & 61 & $\begin{array}{c}234-268 \\
(234-236)\end{array}$ \\
\hline mAoR17 & $\begin{array}{l}\text { F: GCAATGTGCAGACATGGTTC } \\
\text { R: GGTTTCGCATGGAAGAAGAG }\end{array}$ & $(\mathrm{GA})_{24}$ & 56 & $\begin{array}{c}150-170 \\
(124-159)\end{array}$ \\
\hline mAoR29 & $\begin{array}{l}\text { F: GGAGAAGAAAAGTTAGGTTTGAC } \\
\text { R: CGTCTTCTTCCACATGCTTC }\end{array}$ & $(\mathrm{TG})_{10}$ & 61 & $\begin{array}{c}312-382 \\
(316-320)\end{array}$ \\
\hline mAoR42 & $\begin{array}{l}\text { F: ACTGTCACGTCAATGGCATC } \\
\text { R: GCGAAGGTCAAAGAGCAGTC }\end{array}$ & $(\mathrm{CAT})_{9} \mathrm{TAT}(\mathrm{CTT})_{7}$ & 60 & $\begin{array}{c}197-205 \\
(197-206)\end{array}$ \\
\hline mAoR46 & $\begin{array}{l}\text { F: CGGCGTCGTTAAAGCAGT } \\
\text { R: TCCTCCTCCGTCTCACTTTC }\end{array}$ & $(\mathrm{ACC})_{7}(\mathrm{AC})_{3}$ & 61 & $\begin{array}{c}216-252 \\
(217-221)\end{array}$ \\
\hline mAoR48 & $\begin{array}{l}\text { F: CAGCGAGTGGCTTACGAAAT } \\
\text { R: GACCATGGGCTTGATACGTC }\end{array}$ & $(\mathrm{GAA})_{6}(\mathrm{GA})_{3}$ & 59 & $\begin{array}{c}184-188 \\
(172-178)\end{array}$ \\
\hline mAoR52 & $\begin{array}{l}\text { F: GCTATGACCCTTGGGAACTC } \\
\text { R: GTGACACAACCAAAACCACA }\end{array}$ & $(\mathrm{GT})_{16}(\mathrm{TA})_{2}$ & 60 & $\begin{array}{c}198-220 \\
(191-203)\end{array}$ \\
\hline mAoR55 & $\begin{array}{l}\text { F: TGACTTTCAAATGCCACAAC } \\
\text { R: CTCAAGCTTTCATGGGGATT }\end{array}$ & $(\mathrm{AT})_{6} \mathrm{CT}(\mathrm{AC})_{5}$ & 60 & $\begin{array}{c}224-274 \\
(104-114)\end{array}$ \\
\hline
\end{tabular}

$\mathrm{Tm}=$ annealing temperature adjusted for each pair of primers in $A$. humile; AAS = amplitude of allelic size (bp) found in A. humile, values in parentheses are the AAS found in A. occidentale. 
All reactions were performed using a Veriti Thermal Cycler (Applied Biosystems, CA, USA), according to a PCR protocol that consisted of a preliminary denaturation step at $94^{\circ} \mathrm{C}$ for $5 \mathrm{~min} ; 35$ cycles of $94^{\circ} \mathrm{C}$ for $1 \mathrm{~min}$, the annealing temperature established for each pair of primers for $1 \mathrm{~min}$, and $72^{\circ} \mathrm{C}$ for $1 \mathrm{~min}$, and a final extension step at $72^{\circ} \mathrm{C}$ for $7 \mathrm{~min}$.

The PCR products were separated on a $5 \%$ polyacrylamide gel by electrophoresis with $1 X$ Tris-borate-EDTA buffer and were stained with $1 \mathrm{mg} / \mathrm{mL}$ ethidium bromide. A 50-bp molecular weight marker was used to estimate the size of the alleles.

\section{Characterization of loci}

The number of alleles per loci, observed heterozygosity $\left(H_{\mathrm{O}}\right)$, and expected heterozygosity $\left(H_{\mathrm{E}}\right)$ under Hardy-Weinberg equilibrium and Wright's fixation index $(f)$ were estimated using the GDA 1.1 Genetic Data Analysis software (Lewis and Zaykin, 2001). The deviation from Hardy-Weinberg equilibrium and the linkage disequilibrium for pairs of loci were examined using the FSTAT 2.9.3.2 program with Bonferroni's correction (Goudet, 2002). The probability of genetic identity $(I)$ (Chakravarat and Li, 1983) and the probability of paternity exclusion $(Q)$ (Weir, 1996) were estimated from the frequency of alleles at each locus. The combined probabilities of paternity exclusion $(Q C)$ and genetic identity $(I C)$ were calculated using the following formulae: $Q C=1-[\Pi(1-Q i)]$ and $I C=\Pi I i$. The Micro-Checker 2.2.3 program (Van Oosterhout et al., 2004) was used to assess the presence of null, stutter, and dropout alleles in $A$. humile genotypes (Table 1).

\section{RESULTS AND DISCUSSION}

\section{Transferability of SSR markers}

Successful amplification of the 11 SSR markers was achieved in A. humile with $100 \%$ polymorphism (Table 2). The amplitude of allele-size found in A. humile loci was close to the expected interval based on A. occidentale, except for the mAoR55 locus, which showed an allele-size that was larger than the predicted value (Table 1).

Similar transferability rates for microsatellite markers with high levels of polymorphism have been reported in other studies of plants such as Arachis (Bravo et al., 2006) and Hymenaea (Ciampi et al., 2008) or those from different genera such as among the species of the Poaceae family (Elazreg et al., 2011). These results demonstrate that several species, which may or may not be closely related, can be analyzed without the need for designing specific primers. Rossetto (2001) has suggested that finding functional SSR primers is possible even among distantly related species. However, according to Jensen et al. (2007), a higher transferability rate is positively correlated, in general, with the phylogenetic relationship between species. Therefore, the efficacy of SSR marker transferability from A. occidentale to A. humile reflects the conservation of regions between these congeneric species with homology in the microsatellite flanking regions. Moreover, the potential for using these markers for genomic analyses of populations of this species is highlighted by the percentage of polymorphic loci.

\section{Characterization of the polymorphic SSR loci}

A total of 59 alleles were generated, with an average of 5.4 alleles per locus. We 
observed loci with 3 (mAoR7 and mAoR48) to 8 (mAoR11) alleles. The average number of alleles per locus was less than those found for Eugenia dysenterica (10.4) (Zucchi et al., 2002) and Festuca arundinacea (7.8) (Elazreg et al., 2011). The observed number of alleles per locus was closer to the values observed for Hymenaea stigonocarpa (6.43) (Ciampi et al., 2008), Dactylis glomerata (5.45), Lolium perenne (4.50) (Litrico et al., 2009) and Blighia sapida (3.7) (Ekué et al., 2009). Albaladejo et al. (2008) suggested that the number of alleles per locus observed for microsatellite loci in Pistacia lentiscus (3-13 alleles) provides highly informative content for the loci in population studies. Similarly, the richness of alleles for loci found in the present study may be useful for future research on the species.

The maximum number of alleles per locus was 5 in $A$. occidentale. This maximum number was found at locus mAoR17 (Croxford et al., 2006), which showed 4 alleles in $\mathrm{A}$. humile. However, among the other markers analyzed in this study, the number of alleles per locus was higher in A. humile than in A. occidentale. Croxford et al. (2006) suggested that the close genetic relationship of the sampled trees resulted in the limited number of alleles detected in $A$. occidentale. A greater number of alleles was detected for $B$. sapida in natural populations than in planted populations, and the level of heterozygosity was also lower in the planted populations (Ekué et al., 2009). Thus, the results observed for $A$. humile indicate that the individuals sampled for the characterization of the loci show considerable variation because they belong to natural populations of this species.

The $H_{\mathrm{O}}$ was lower than the $H_{\mathrm{E}}$ under Hardy-Weinberg equilibrium for 7 of the 11 loci analyzed. Heterozygosity ranged from 0 (mAoR07 and mAoR48 loci homozygotes) to 0.545 (mAoR55 locus). An excess of heterozygotes was observed for the mAoR03, mAoR06, mAoR29, and mAoR46 loci because $H_{\mathrm{O}}$ was higher than $H_{\mathrm{E}}$ for these loci; however, the mean value for $H_{\mathrm{O}}(0.463)$ was lower than that for $H_{\mathrm{E}}(0.696)$. Consequently, positive and significant values for the coefficient of endogamy $(f)$ were observed for most loci. Only the mAoR03, mAoR06, mAoR29, and mAoR46 loci were in Hardy-Weinberg equilibrium, with values of $f$ that were not significantly different from $0(\mathrm{P}>0.00455)$ (Table 2). Similar results for $H_{\mathrm{E}}$ and $H_{\mathrm{O}}$ were found in a population of $P$. lentiscus $\mathrm{L}$. by using specific microsatellite markers $\left(H_{\mathrm{E}}\right.$ ranged from 0.291 to 0.848 and $H_{\mathrm{O}}$ from 0.143 to 0.762 ) (Albaladejo et al., 2008). The mean values for $H_{\mathrm{O}}$ and $H_{\mathrm{E}}$ were also close to those found with heterologous SSR in $H$. stigonocarpa (0.389 and 0.601, respectively) (Ciampi et al., 2008) and in 2 populations of Tabebuia roseoalba (with average $H_{\mathrm{O}}$ of 0.416 and 0.490 and $H_{\mathrm{E}}$ of 0.773 and 0.740 ) (Feres et al., 2009).

Table 2. Characterization of loci for microsatellites of 40 adult individuals of Anacardium humile.

\begin{tabular}{lcccccc}
\hline Locus & $A$ & $H_{\mathrm{E}}$ & $H_{\mathrm{O}}$ & $f$ & $Q$ & $I$ \\
\hline mAoR03 & 6 & 0.653 & 0.667 & $-0.022^{\text {ns }}$ & 0.412 & 0.186 \\
mAoR06 & 5 & 0.709 & 0.975 & $-0.381^{\text {ns }}$ & 0.475 & 0.144 \\
mAoR07 & 3 & 0.556 & 0.000 & 1.000 & 0.297 & 0.287 \\
mAoR11 & 8 & 0.801 & 0.536 & 0.335 & 0.465 & 0.074 \\
mAoR17 & 4 & 0.695 & 0.275 & 0.608 & 0.636 & 0.148 \\
mAoR29 & 7 & 0.816 & 0.925 & $-0.136^{\text {ns }}$ & 0.467 & 0.148 \\
mAoR42 & 4 & 0.708 & 0.097 & 0.865 & 0.583 & 0.087 \\
mAoR46 & 7 & 0.780 & 0.872 & $-0.119^{\text {ns }}$ & 0.05 & 0.116 \\
mAoR48 & 3 & 0.423 & 0.000 & 1.000 & 0.521 & 0.094 \\
mAoR52 & 5 & 0.745 & 0.200 & 0.734 & 0.294 & $I C=3.13 \times 10^{-10}$ \\
mAoR55 & 7 & 0.769 & 0.545 & 0.338 & 0.9994 & .
\end{tabular}

$A=$ number of alleles per locus; $H_{\mathrm{E}}=$ expected heterozygosity; $H_{\mathrm{O}}=$ observed heterozygosity; $f=$ coefficient of endogamy; $Q$ = probability of paternity exclusion; $I=$ probability of genetic identity; $Q C=$ combined probability of paternity exclusion; $I C=$ combined probability of genetic identity. $\mathrm{ns}=$ non-significant values $(\mathrm{P}>0.00455)$. 
We found $100 \%$ homozygotes at 2 loci (mAoR07 and mAoR48), with $H_{\mathrm{O}}$ equal to 0 . At 6 and 10 loci, at least 53.6 and 55.6\%, respectively, of the individuals were heterozygotes. These estimates reveal a satisfactory level of heterozygosity for diagnosing the levels of genetic diversity in populations. This level of heterozygosity is also effective for breeding programs and genetic mapping, in accordance with approaches described by other authors (Ciampi et al., 2008; Feres et al., 2009; Cristofani-Yaly et al., 2011).

The $Q C$ was high. The value was highest for the mAoR11, mAoR29, mAoR46, and mAoR55 loci, which exhibited a greater number of alleles per locus, and lowest for the mAoR07 and mAoR48 loci, which exhibited fewer alleles. The $I C$ was low because several loci showed low values for the probability of genetic identity (Table 2). No linkage disequilibrium was found among the pairs of loci analyzed.

Few loci did not have significant values for the coefficient of endogamy, with high $Q C$ values and low $I C$ values. Furthermore, none of the pairs of loci showed linkage disequilibrium in A. humile. However, the transferred microsatellite markers are suitable for studies of kinship, in accordance with the results observed in A. occidentale, in which all loci showed independent behavior (Croxford et al., 2006). Collevatti et al. (1999) have suggested that the high combined probability of paternity exclusion (0.99) found for SSR markers developed for Caryocar brasiliense enables detailed studies of kinship in natural populations, even without a priori knowledge of maternity and paternity of the individuals. Similarly, for P. lentiscus, polymorphic SSR markers provide enough variation (and probability of exclusion $>99 \%$ ) to enable studies of patterns of gene flow (Albaladejo et al., 2008), which provides useful information for conservation programs and restoration of species. The analyses indicate that null alleles may be present at most loci because of excess homozygotes. The presence of stutter may have generated a genotyping error only at the mAoR48 loci, and no evidence of dropout was found for any of the loci. Evidence for the presence of null alleles may not be a feature of loci but of individuals in the population sampled, according to the suggestions of Ciampi et al. (2008). An analogous result has been reported for T. roseo-alba, for which the presence of null alleles was suggested for most loci examined. However, examination of the mating system in populations revealed that the presence of null alleles was detected at few loci (Feres et al., 2009). Dev et al. (2011) have reported that the presence of null alleles does not change the spatial genetic structure in Ficus hispida and F. exasperata because similar spatial genetic structure values were also found when using only those loci that showed no sign of null alleles.

\section{CONCLUSION}

The transfer of all SSR markers to A. humile was successfully accomplished. Because of the high information content offered, the markers transferred and characterized in this study are robust tools for genetic analyses of populations of A. humile and genetic diversity, partitioning of genetic variation within and among natural populations, mating systems, gene flow, genomic mapping, and evolutionary relationships.

\section{ACKNOWLEDGMENTS}

Research support by FAPEMIG (\#APQ-02003-09) through an Incentive to Research and Technological Development Grant (BIPDT) for D.A. Oliveira and a Training Program grant (PCRH) for A.F. Melo Júnior. We also acknowledge CAPES for the Master's scholar- 
ship for G.C. Cota and Doctoral scholarship for P.A. Moreira. The State Forestry Institute (IEF) provided assistance in collecting the samples and data. Finally, we acknowledge Montes Claros State University (UNIMONTES) for logistical support.

\section{REFERENCES}

Albaladejo RG, Sebastiani F, Aparicio A, Buonamici A, et al. (2008). Development and characterization of eight polymorphic microsatellite loci from Pistacia lentiscus L. (Anacardiaceae). Mol. Ecol. Resour. 8: 904-906.

Almeida SP, Proença CEB, Sano SM and Ribeiro JF (1998). Cerrado: Useful Plant Species. Embrapa, CPAC, Planaltina.

Barbará T, Palma-Silva C, Paggi GM, Bered F, et al. (2007). Cross-species transfer of nuclear microsatellite markers: potential and limitations. Mol. Ecol. 16: 3759-3767.

Bravo JP, Hoshino AA, Angelici CMLCD, Lopes CR, et al. (2006). Transferability and use of microsatellite markers for the genetic analysis of the germplasm of some Arachis section species of the genus Arachis. Genet. Mol. Biol. 29: 516-524.

Chakravarat I and Li CC (1983). The Effect of Linkage on Paternity Calculations. In: Inclusion Probabilities in Parentage Testing (Walkera RH, ed.). American Association of Blood Banks, Arlington.

Ciampi AY, Azevedo VC, Gaiotto FA, Ramos AC, et al. (2008). Isolation and characterization of microsatellite loci for Hymenaea courbaril and transferability to Hymenaea stigonocarpa, two tropical timber species. Mol. Ecol. Resour. 8: 1074-1077.

Collevatti RG, Brondani RV and Grattapaglia D (1999). Development and characterization of microsatellite markers for genetic analysis of a Brazilian endangered tree species Caryocar brasiliense. Heredity 83: 748-756.

Cristofani-Yaly M, Novelli VM, Bastianel M and Machado MA (2011). Transferability and level of heterozygosity of microsatellite markers in Citrus species. Plant Mol. Biol. Rep. 29: 418-423.

Croxford AE, Robson M and Wilkinson MJ (2006). Characterization and PCR multiplexing of polymorphic microsatellite loci in cashew (Anacardium occidentale L.) and their cross-species utilization. Mol. Ecol. Notes 6: 249-251.

Dev SA, Kjellberg F, Hossaert-McKey M and Borges RM (2011). Fine-scale population genetic structure of two dioecious indian keystone species, Ficus hispida and Ficus exasperata (Moraceae). Biotropica 43: 309-316.

Doyle JJ and Doyle JL (1987). Isolation of plant DNA from fresh tissue. Focus 12: 13-15.

Ekué MRM, Gailing O and Finkeldey R (2009). Transferability of simple sequence repeat (SSR) markers developed in Litchi chinensis to Blighia sapida (Sapindaceae). Plant Mol. Biol. Rep. 27: 570-574.

Elazreg H, Ghariani S, Chtourou-Ghorbel N, Chakroun M, et al. (2011). SSRs transferability and genetic diversity of Tunisian Festuca arundinacea and Lolium perenne. Biochem. Syst. Ecol. 39: 79-87.

Ellegren H (2004). Microsatellites: simple sequences with complex evolution. Nat. Rev. Genet. 5: 435-445.

Ellis JR and Burke JM (2007). EST-SSRs as a resource for population genetic analyses. Heredity 99: 125-132.

Feres JM, Martinez ML, Martinez CA, Mestriner MA, et al. (2009). Transferability and characterization of nine microsatellite markers for the tropical tree species Tabebuia roseo-alba. Mol. Ecol. Resour. 9: 434-437.

FitzSimmons NN, Moritz C and Moore SS (1995). Conservation and dynamics of microsatellite loci over 300 million years of marine turtle evolution. Mol. Biol. Evol. 12: 432-440.

Goudet J (2002). FSTAT, A Program to Estimate and Test Gene Diversities and Fixation Indices (Version 2.9.3.2). Available at [http://www.unil.ch/izea/softwares/fstat.html]. Accessed August 16, 2011.

Guichoux E, Lagache L, Wagner S, Chaumeil P, et al. (2011). Current trends in microsatellite genotyping. Mol. Ecol. Resour. 11: 591-611.

Hardy OJ, Maggia L, Bandou E, Breyne P, et al. (2006). Fine-scale genetic structure and gene dispersal inferences in 10 neotropical tree species. Mol. Ecol. 15: 559-571.

Jensen LB, Holm PB and Lubbersted T (2007). Cross-species amplification of 105 Lolium perenne SSR loci in 23 species within the Poaceae. Mol. Ecol. Notes 7: 1155-1161.

Lewis PO and Zaykin D (2001). Genetic Data Analysis: Computer Program for the Analysis of Allelic Data. Version 1.0 (d16c). Available at [http://hydrodictyon.eeb.uconn.edu/people/plewis/software.php]. Accessed August 16, 2011.

Litrico I, Bech N, Flajoulot S, Cadier D, et al. (2009). Cross-species amplification tests and diversity analysis using 56 PCR markers in Dactylis glomerata and Lolium perenne. Mol. Ecol. Resour. 9: 159-164.

Londe LN, Sousa CS, Vieira CU, Bonetti AM, et al. (2007). Effect of benomyl and identification of plant pathogens in MS media for contamination control in Anacardium humile (Anacardiaceae) micropropagation. Biosci. J. 23: 94-100.

Moore SS, Sargeant LL, King TJ, Mattick JS, et al. (1991). The conservation of dinucleotide microsatellites among mammalian genomes allows the use of heterologous PCR primer pairs in closely related species. Genomics 10: 654-660. 
Oliveira EJ, Pádua JG, Zucchi MI, Vencovsky R, et al. (2006). Origin, evolution and genome distribution of microsatellites. Genet. Mol. Biol. 29: 294-307.

Ribeiro RA and Rodrigues FM (2006). Genética da conservação em espécies vegetais do Cerrado. R. Ci. Med. Biol. 5: 253-260.

Rosseto M (2001). Sourcing of SSR Markers from Related Plant Species. In: Plant Genotyping: The DNA Fingerprinting of Plants (Henry RJ, ed.). CABI, Wallingford, 211-224.

Schlotterer C, Amos B and Tautz D (1991). Conservation of polymorphic simple sequence loci in cetacean species. Nature 354: 63-65.

Takezaki N and Nei M (2008). Empirical tests of the reliability of phylogenetic trees constructed with microsatellite DNA. Genetics 178: 385-392.

Tautz D (1989). Hypervariability of simple sequences as a general source for polymorphic DNA markers. Nucleic Acids Res. 17: 6463-6471.

Van Oosterhout C, Hutchinson WF, Wills DPM and Shipley P (2004). Micro-checker: software for identifying and correcting genotyping errors in microsatellite data. Mol. Ecol. Notes 4: 535-538.

Vieira RF, Costa TSA, Silva DB, Ferreira FR, et al. (2006). Fruits Native to the Midwest Region of Brazil. Embrapa Genetic Resources and Biotechnology, Brasília.

Weber JL and May PE (1989). Abundant class of human DNA polymorphisms which can be typed using the polymerase chain reaction. Am. J. Hum. Genet. 44: 388-396.

Weir BS (1996). Genetic Data Analysis II. Methods for Discrete Population Genetic Data. Sinauer Associates, Sunderland.

Zucchi MI, Brondani RPV, Pinheiro JB, Brondani C, et al. (2002). Transferability of microsatellite markers from Eucalyptus spp. to Eugenia dysenterica (Myrtaceae family). Mol. Ecol. Notes 2: 512-513.

Zucchi MI, Brondani RPV, Pinheiro JB, Chaves LJ, et al. (2003). Genetic structure and gene flow in Eugenia dysenterica DC in the Brazilian Cerrado utilizing SSR markers. Genet. Mol. Biol. 26: 449-457. 